\title{
Drug utilization study in orthopaedic units: Antibiotics prescribed in hospital out-patients in Dhaka, Bangladesh
}

\author{
*Seheli Sejuti Bithi' ${ }^{1}$ Md. Minhazur Rahman Khan ${ }^{1}$, Ahsan Ullah Khan² \\ ${ }^{1}$ Department of Pharmacy, Jahangirnagar University, Savar, Dhaka, Bangladesh \\ ${ }^{2}$ Department of Pharmacy, University of Asia Pacific, Dhaka Bangladesh
}

\begin{abstract}
Antibiotics are generally prescribed for both as prophylactically (before orthopaedics surgery etc.) or to treat ongoing infection (like septic arthritis, osteomyelitis etc.) in the orthopaedics department. But if antibiotics are not use rationally then there will be increase chances of resistance of bacteria as also as deteriorate the patients' disease condition which ultimately increase the total cost of treatment. The goal of this study was to see the antibiotics utilization pattern. A prospective cross-sectional, multicentre drug utilization study was conducted for a period of 3 months to evaluate the pattern of antibiotics use in orthopaedic unit of various hospitals of Dhaka City, Bangladesh. A total of 498 prescriptions were studied; in which 160 prescriptions contained mono-antibiotic therapy $(51.79 \%)$ and 147 prescriptions contained poly-antibiotics therapy $(48.21 \%)$ and the beta-lactam antibiotics were most commonly prescribed $(81.68 \%)$. Mono-antibiotics prescriptions were the common pattern than combination and brand name has been prescribed frequently than generic. To minimize cost, it is advisable to promote prescription of generic drugs. Also justifying efforts are needed to improve appropriateness of antimicrobial therapy and minimize the development of antimicrobial resistance. Hence the results of the study showed that there is a considerable scope for improvement in the prescription pattern.
\end{abstract}

Key Words: Drug utilization study, antibiotics, unicentric study

\section{INTRODUCTION}

Drug utilization (DU) studies are very important factor of almost all therapeutic drugs such as antibiotics or other constitutes which has a strong therapeutic outcome. The World Health Organization (WHO) addressed Drug utilization as the marketing, distribution, prescription, and use of drugs in a society, with special emphasis on the resulting medical, social and economic consequences (WHO Expert Committee, 1977). A number of factors (prescribing, dispensing, administering, and taking of medication) and its associated events, covering the medical and non-medical determinants are focuses on drug utilization. The effects of drug utilization also deal on how drug utilization relates to the use of drug, beneficial or adverse effects (Lunde et al., 1988; Strom, 2005; Costa et al., 2001). In order to develop drug therapy, the therapeutic practice is has to be evidence-based which comes up by pre-marketing clinical trials and after getting feedback from patients for long time use and also complementary data is required from post marketing period (Strom, 1985).

Antibiotics are possibly the most vital advancement in the history of medicine and undoubtedly; they are among medicine's most prevailing sector (Doyne et al., 2004; Austin et al., 1999). Infrequent uses of antibiotics increases the chances of the bacterial resistance (Austin et al., 1999). Problems associated with the development and spread of antibiotic resistance in hospitals have been increasing since the early 1960s and are currently viewed as a major risk to clinical practice with significant mortality and health care costs. In this regards, many experts deemed that inappropriate and overuse of

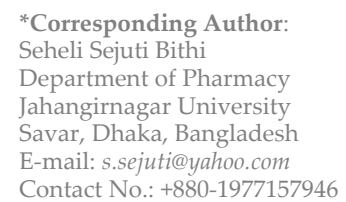

antibiotics must be reduced if we are going to lessen the prevalence of bacterial resistance (Tomasz et al., 1994).

Antibiotics are frequently prescribed medicine in orthopaedics unit (Yusof et al., 2004). The antibiotics are prescribed both as prophylactically (before orthopaedics surgery etc.) or to treat current infection (septic arthritis, osteomyelitis etc.) (Norden, 1976). Infection is a very prevailing problem in the orthopaedic surgery because of its continuing incidence, clinical importance and serious sequels, the treatment being very difficult and expensive. Rates of infection have been reduced by antibiotic prophylaxis, but the increasing number of implants used means that there are still many patients affected every year (Lazzarini et al., 2005). Implants are avascular in type and so antibiotics can get into them only by the process of diffusion from the surrounding tissues. Infection which is happened by an implant cannot be cured simply with antibiotics and it often demands the surgical removal of the implant (Purghel et al., 2006).

This drug utilization study was conducted to study antibiotics usage in orthopaedics department of various hospitals for two main reasons. Firstly, a large number of antibiotics are being used now-a-days and also, lifethreatening antibiotic resistance can result due to its irrational use.

\section{MATERIALS AND METHODS}

This prospective cross-sectional, multicentre survey was carried out to describe the current prescribing practices at hospital orthopaedic out-patients from June 2013 to August 2013. Two qualified pharmacists and three undergraduate pharmacy students were engaged to collect data form orthopaedic unit of hospitals in Dhaka, Bangladesh.

Total 498 prescriptions were collected from the aforesaid locations. All the patients using antibiotics, between 18-60 years of age, irrespective of gender, type of infection, type of antimicrobial prescribed, prescribed in generic form, average numbers of drugs per prescription were studied. No follow up of prescription was done. All 
Table 1: Demographic profile of patients in orthopaedic units of hospitals in Dhaka, Bangladesh.

\begin{tabular}{cc}
\hline Variables & Values $\mathbf{( \% )}$ \\
\hline Total number of prescriptions & 498 \\
Male & $315(63.25)$ \\
Female & $183(36.75)$ \\
Age range & $6-82$ years \\
$\%$ of patients below 18 years & $74(14.85)$ \\
$\%$ of patients 18-30 years & $120(24.09)$ \\
$\%$ of patients 31-60 years & $220(44.17)$ \\
$\%$ of patients $>60$ years & $84(16.86)$ \\
Total number of drugs & 2489 \\
Number of drugs per prescription & 4.79 \\
1-2 & $77(15.46)$ \\
$3-5$ & $306(61.44)$ \\
6-9 & $82(16.46)$ \\
$\geq 10$ & $33(6.62)$ \\
\hline
\end{tabular}

data were first analyzed manually and then using Microsoft ${ }^{\circledR}$ Excel 2007. In the statistical analysis, frequencies, averages/means, standard deviations and percentages were obtained.

\section{RESULTS}

Prescription pattern

Of the 498 prescriptions there were total 2489 drugs used for the treatment of the patients. Table 1 shows the demographic profile of the study population. The majority of the patients attending in the hospital were male $(63.25 \%)$. The age of the patients ranged from 6 to 82 years with an average of years where almost half of the patients highest prevalence of diseases was above 30 years old. The total number of medications per prescription was of 2 to 14. The study of number of drug per prescription showed that about $61.44 \%$ prescriptions $(n=306)$ contained $3-5$ drugs whereas $6.62 \%$ prescriptions $(n=33)$ had more than ten drugs.

\section{Antibiotic prescription pattern}

A total of 308 prescriptions (62\%) contained antibiotics where majority of patients treated as monotherapy which is about $52 \%$ with followed by $9 \%$ of combination of triple antibiotic. Only $10 \%$ of drugs were prescribed by generic name (table 2).

When prescriptions were screened thoroughly, the number of prescriptions of mono-antibiotic prescription (single antibiotic/prescription) was 160 (51.79\%) where prescriptions containing two-antibiotic therapy were 122 $(39.49 \%) \&$ combination of triple antibiotic was the
Table 2: Prescription pattern of antibiotic.

\begin{tabular}{lc}
\hline Variables & Values (\%) \\
\hline Number of prescriptions with antibiotic(s): & $308(61.90)$ \\
Mono antibiotic therapy & $160(51.95)$ \\
Antibiotic combination (two) therapy & $121(39.29)$ \\
Antibiotic combination (three) therapy & $27(8.76)$ \\
Antibiotics prescribed in form of ${ }^{* *}:$ & $277(89.93)$ \\
Brand & $31(10.06)$ \\
Generic & \\
${ }^{*} \mathrm{~N}=498 \quad{ }^{* *} \mathrm{~N}=308$ &
\end{tabular}

poorest $(8.72 \%)$. Among the mono-antibiotic therapy, cefixime was prescribed most commonly (170 prescription) and cefuroxime was the least (7 prescription). Most commonly prescribed category of antibiotics was found to be beta-lactam $(81.69 \%)$ followed by fluoroquinolone $(7.56$ $\%)$ \& macrolide (7\%). Among beta-lactam, cephalosporin was the pioneer with a percentage of $67.26 \%$ \& amongst cephalosporins; cefixime (90\%) was the most common antibiotic. In poly-antibiotic therapy (two), cefixime \& flucloxacillin $(72.96 \%)$ was the pioneer combination in single prescription and in triple therapy, cefixime, flucloxacillin \& ceftriaxone $(77.78 \%)$ was the highly prescribed combination (table 3).

\section{Supportive drugs}

Nutritional supplements as a form of calcium was the highly prescribed $(81.48 \%)$ followed by multivitaminminerals $(73.25 \%)$. This study also demonstrated that the frequency of subsequent use of multivitamin-minerals, calcium-vitamin-D supplement was much (table 4).

\section{Diagnostic pattern}

The present study showed that $32.07 \%$ (table 5) of the patients suffered from accidental trauma which is followed by fracture, joint inflammation \& with the least of organ deformity $(1.6 \%)$.

\section{DISCUSSION}

A prescription by a doctor may be taken as an indication of the doctors' attitude towards the disease and the role of drugs in its treatment. The antibiotic prescription pattern of the study population shows that the average number of drugs per prescription is above 4.7. A study on prescription trends in a tertiary care teaching hospital (Department of Orthopaedics, Mamata Medial College, Khammam, India) shows that the average number of drugs was 2.1 which are much lower than ours (Ubedulla

Table 3: Frequency of prescribed antibiotics.

\begin{tabular}{|c|c|c|c|c|c|}
\hline Class of antibiotics & Generic name & Dosage form & Number & Total Number & Value (\%) \\
\hline \multirow{5}{*}{ Beta-lactam } & Ceftriaxone & Injection & 12 & \multirow{5}{*}{281} & 3.49 \\
\hline & Cefixime & Injection \& Capsule & 170 & & 49.42 \\
\hline & Cefuroxime & Injection & 7 & & 2.03 \\
\hline & Flucloxacillin & Capsule & 84 & & 24.42 \\
\hline & Amoxycillin & Capsule & 8 & & 2.33 \\
\hline Fluoroquinolone & Ciprofloxacin & Tablet & 26 & 26 & 7.56 \\
\hline \multirow{5}{*}{ Others } & Azithromycin (Macrolide) & Tablet & 25 & \multirow{4}{*}{37} & 7.27 \\
\hline & Amikacin (Aminoglycosides) & Injection & 5 & & 1.45 \\
\hline & Cotrimoxazole (Sulfadiazine) & Tablet & 4 & & 1.16 \\
\hline & Doxycycline (Tetracycline) & Tablet & 3 & & 0.87 \\
\hline & & & & Total $=344$ & \\
\hline \multirow{4}{*}{ Combination antibiotic } & Cefixime+Flucloxacillin & \multirow{2}{*}{ Capsule, Tablet, Injection } & 89 & & 72.96 \\
\hline & Others & & 33 & & 27.04 \\
\hline & Ceftriaxone + Cefixime + Flucloxacillin & \multirow{2}{*}{ Injection, Capsule } & 21 & & 77.78 \\
\hline & Others & & 6 & & 22.22 \\
\hline
\end{tabular}


Table 4: Prescribed therapeutic drug classes except antibiotics in orthopaedic unit.

\begin{tabular}{lcc}
\hline \multirow{2}{*}{ Drug class } & \multicolumn{2}{c}{ Number } \\
\cline { 2 - 3 } & Total (n) & \% of Prescription \\
\hline Nutritional supplement & 243 & 48.8 \\
Multivitamin-Multi-minerals & 178 & 73.25 \\
Calcium supplement & 198 & 81.48 \\
Iron supplement & 69 & 28.40 \\
Vitamin B & 106 & 43.62 \\
Vitamin C & 48 & 19.75 \\
\hline
\end{tabular}

et al., 2013). Another study was held in Pokhara, Western Nepal on prescribing patterns in the orthopaedics outpatient department in a teaching hospital shows that the average number of prescribed drugs was 1.9 (Shankar et al., 2007). Similar study was observed in West Bengal, India based on drug utilization study on antibiotics use in an orthopaedics department of a tertiary care hospital where the average number of drugs was 3.4 (Ghosh et al., 2013).

In general practice, the therapeutic approach for orthopaedic infection is primarily empirical and the main aim of the physicians is to treat as specifically as possible. The present study indicates the general trends of use of antibiotics in orthopaedics department.

Demographic characteristics showed that percentage of males suffering from infection was more than females. Further it was noted that a majority of the patients were age group of $31-60$ years $(44.17 \%)$ due to degeneration process of bone or the most vulnerable age of people.

In this study only $18 \%$ of drugs were prescribed by generic name. The percentage a bit higher than that observed in in Mamata Medial College, Khammam in Department of Orthopaedics, India was $4.25 \%$, (Ubedulla et al., 2013) in Pokhara, western Nepal was 19.3\%. (Shankar et al., 2007) and in Karachi, Pakistan was 12\% (Zaidi and Nishtar, 2013). Generic prescribing is to be encouraged as it works out to be cheaper for the patient and the possibility of drug errors is reduced.

This study represent that mono-antibiotic prescription was more preferred than poly-antibiotic therapy. Most commonly prescribed category of antibiotics was found to be beta-lactam \& cefixime was the pioneer one. It was chosen because it is the only oral $3^{\text {rd }}$ generation cephalosporin which has the equivalent efficacy with injectables. In orthopaedics, bone related infections are highly prevalent.

Bone and soft tissue infections are serious problems in orthopaedic and reconstructive surgery. Especially, chronic osteomyelitis is a difficult infection to treat and eradicate. Long term parenteral antibiotics with multiple surgical debridements are often required for effective therapy (Cierny and Mader, 1987). Bacterial infection in orthopaedic and reconstructive surgery can be devastating, and is associated with significant morbidity and poor functional outcomes (Haddad et al., 2000).

The majority of outpatients SSTI are caused by gram-positive bacteria, typically Streptococcus and Staphylococcus species. In the past, SSTI caused by these organisms were reliably treated with beta-lactam antibiotics (penicillins and cephalosporins). Resistance to these antibiotics was uncommon and was typically only seen in infections caused by Staphylococcus aureus that had acquired a gene conferring resistance to all beta-lactams, including the drug methicillin. These resistant infections typically only occurred in hospitalized or recentlyhospitalized individuals (Lee et al., 2005).
Table 5: Diagnostic pattern of orthopaedic outpatients of Dhaka $(\mathrm{N}=498)$.

\begin{tabular}{lcc}
\hline Diagnosis & No. of patients & Prevalence (\%) \\
\hline Accidental trauma & 160 & 32.07 \\
Fracture & 95 & 19.05 \\
Joint inflammation & 90 & 18.10 \\
Dislocation & 73 & 14.61 \\
Osteoarthritis & 28 & 5.72 \\
Surgery & 16 & 3.22 \\
Osteomyelitis & 12 & 2.41 \\
Organ deformity & 8 & 1.61 \\
Others & 16 & 3.22 \\
\hline
\end{tabular}

Ideally, antibiotic selection is based on reliable culture and sensitivity results. In general, antibiotics are initially given parenterally. After 2 weeks of intravenous therapy antibiotics may then be given orally provided an acceptable oral regimen is available.

Supplement of calcium, vitamin-D, and multivitamin-minerals were also prescribed frequently as most of the orthopaedic patients were suffered from bone related problems.

This study was carried out in an urban setting and this may affect how our findings can be extrapolated to the generality of patients, especially those residing in rural areas. Secondly, study population was not large enough to represent the actual scenario of the country. By considering larger sample size, the result may vary.

\section{CONCLUSION}

The study presents the prescription trends of antibiotics in orthopaedic outpatient of different hospitals of Dhaka, Bangladesh. This kind of study will help as a guideline to use antibiotic for policymaking decision in the health care system. There is a considerable scope of improvement in the prescribing practices, especially prescribing by generic names which has less financial burden on patients, so prescription of drugs from a hospital formulary has to be encouraged for the purpose. Prescribing medicines by generic names would help in less expensive treatment. The number of medicines per prescription should be kept in minimum. In other words rational drug must be strictly followed. Polypharmacy and combination of drugs has to be discouraged to minimize adverse drug reactions and drug interactions. So monitoring of use of antibiotic is very crucial in this time.

Though pharmacovigilance is still in its infancy in Bangladesh, this is likely to expand in the times to come. This is because as the newer and newer antibiotics hit the market, the need for pharmacovigilance grows more than ever before. Pharmacovigilance is an important tool for the treating physician to develop safe medical practice. Identifying the adverse drug events, resistance, efficacy, recording them meticulously and reporting them to the concerned authority is a valuable task in medical profession. This practice will prove to be very valuable in making the drug therapy safer and rational.

\section{ACKNOWLEDGEMENT}

The authors are grateful to the Department of Pharmacy of the University of Asia Pacific for supporting us to conduct the survey based health research. Lastly, we would like to thank all the patients who agreed to participate in the study. Without their prescription, the study would not have been possible. 


\section{REFERENCES}

Austin DJ, Kristinsson KG and Anderson RM (1999): The relationship between the volume of antimicrobial consumption in human communities and the frequency of resistance. Proc. Natl. Acad. Sci. USA; 96:11526. [DOI]

Cierny G \& Mader JT. (1987). Approach to Adult Osteomyelitis. Orthopaedic Review, Vol.16, No 4, pp. 259-270. PMid:3454938

Costa J, Rosa MM, Ferreira JJ, Sampaio C, Vaz Carneiro A. (2001) Cardiac effects of acute poisoning with tricyclic antidepressants: systematic review of the literature. Part I, Rev Port Cardiol; 20:671-8.

Doyne EO, Alfaro MP, Siegel RM, Atherton HD, Schoettker PJ, Bernier J and Kotagal UR (2004): A randomized controlled trial to change antibiotic prescribing patterns in a community. Arch. Pediatr. Adolesc. Med.; 158: 577-83. [DOI]

Essack SY, Connolly C and Sturm AW (2005): Antibiotic use and resistance in public-sector hospitals in KwaZulu-Natal.S. Afr. Med. J.; 95: 865-70. PMid:16344884

Ghosh AK, Dalai Chanchal Kumar, Kumar Ajay and Ray Madhumita. (2013) Drug utilization study on antibiotics use in an orthopaedics department of a tertiary care hospital in west Bengal, India. Journal of Drug Delivery \& Therapeutics, 3(2), 98-103.

Haddad Fs. Muirhead-Allwood Sk., Manktelow AR., \& Bacarese-Hamilton I. (2000). Two stages uncommented. Revision hip arthroplasty for infection. Journal of bone joint surgery, Vol. 82-6, No 5, pp.689-694

Lazzarini, L, Benjamin A. Lipsky, Jon T. Mader. (2005) Antibiotic treatmen of osteomyelitis: what have we learned from 30 years of clinical trials? International Journal of Infectious Diseases; 9:127-138. [DOI]

Lee, N. and others. (2005) Risk factors for community-associated methicillin-resistant Staphylococcus aureus skin infections among HIVpositive men who have sex with men. Clinical Infectious Diseases 40(10):1529-34. [DOI]
Lunde PK, Baksaas I. (1988) Epidemiology of drug utilization basic concepts and methodology, Acta Med Scand Suppl, 721:7-11. PMid:3281414

Norden CW (1976). Antibiotic prophylaxis in orthopaedic surgery, Clin Orthop Relat Res; 114:203-6. PMid:770037

Purghel F, Badea R, Ciuvica R, Anastasiu A (2006). The use of antibiotics in traumatology and orthopaedic surgery. Mædica - a Journal of Clinical Medicine; 1(3):58-65

Shankar PR, Pai R, Dubey AK, Upadhyay DK. (2007) Prescribing patterns in the orthopaedics outpatient department in a teaching hospital in Pokhara, Western Nepal. Kathmandu University Medical Journal, Vol. 5, No. 1, Issue 17, 16-21.

Strom BL, Melmon KL, Miettinen OS. (1985) Post-marketing studies of drug efficacy, Arch Intern Med; 145:1791-4. [DOI]

Strom BL. (2005) Pharmacoepidemiology. Fourth ed: John Wiley\& Sons, Ltd.

Tomasz A (1994): Multiple-antibiotic resistant pathogenic bacteria. A report on the Rockefeller University workshop. N. Engl. J. Med.; 330:1247-51. [DOI]

Ubedulla, S, Sekhar, NC, Jayasree, T, Shankar J. and Rohit K (2013) Prescription trends in department of orthopaedics at tertiary care teaching hospital. Journal of Chemical and Pharmaceutical Research 5(11):512-517.

WHO Expert Committee. (1977) The Selection of Essential Drugs, Technical Report Series no.615, Geneva: World Health Organization.

Yusof, MI, Yusof, AH (2004) Orthopaedic Infections: Organisms and Antibiotic Sensitivity, Med J Malaysia; 59(5):574-7. PMid:15889557

Zaidi, S and Nishtar NA (2013) Rational prescription \& Use: A snapshot of the evidence from Pakistan and emerging concerns. Int J Pharm Pharm Sci, Vol 5, Suppl. 1, 131-135. 